\title{
Percutaneous Disc Decompression for the Treatment of Chronic Atypical Cervical Discogenic Pain
}

\author{
Vijay Singh, MD \\ Percutaneous disc decompression with \\ the radiofrequency coblation technique has \\ been described to treat contained, symptom- \\ atic lumbar disc herniations. In symptomat- \\ ic cervical disc herniations it has been used \\ very selectively. \\ We report a 42-year-old female with \\ cervical disc pathology, predominantly at \\ $\mathrm{C} 6 / \mathrm{C}_{7}$, treated with percutaneous disc de- \\ compression using coblation technology. Her \\ complaint of cervicogenic cephalgia com- \\ pletely resolved, along with an $85 \%$ reduc- \\ tion of neck pain and upper extremity pain 6 - \\ months post-operatively. \\ This is the first case report of chronic \\ cervical discogenic pain being treated with \\ this technique. \\ Keywords: Cervical disc herniation, \\ neck pain, cervicogenic headache, discogra- \\ phy, percutaneous disc decompression, co- \\ blation technology
}

Among the chronic pain problems emanating from various structures of the spine, the lifetime prevalence of spinal pain has been reported as $65 \%$ to $80 \%$ in the neck and low back (1-8). Linton et al (8) estimated the prevalence of spinal pain in the general population as $66 \%$, with $44 \%$ having pain in the cervical region and $56 \%$ in the lumbar region. In contrast, some authors have reported that neck pain is as prevalent as low back pain or sometimes is even more prevalent ( 9 , $10)$.

Côté et al (2) assessed the prevalence of neck pain and its impact on the general health in the Canadian population showing that 39\% presented with Grade I neck pain with low pain intensity and low disability; 9\% presented with Grade II neck pain with high pain intensity and low disability; and 5\% presented with Grade III neck pain with high pain intensity and moderate disability and Grade IV neck pain with high pain intensity and severe disability. Thus, a total of $5 \%$ of the population with neck pain suffer with high pain intensity coupled with moderate or severe disability. An additional 9\% suffer with neck pain with high pain intensity but with low disability.

From Pain Diagnostics Associates Niagara, Wisconsin. Address Correspondence: Vijay Singh, MD, Pain Diagnostics Associates, 1601 Roosevelt Rd, Niagara, WI 54151

E-mail:vsingh@netnet.net

Funding: There was no external funding in preparation of this manuscript

Conflict of Interest: None
Chronic persistent neck pain has been reported to result in $26 \%$ to $44 \%$ of the patients after an initial episode of neck pain or whiplash $(9,11-14)$.

Kuslich et al (15) identified intervertebral discs, facet joints, nerve root dura, ligaments, fascia, and muscles as tissues capable of transmitting pain in the low back. Thus, the structures responsible for pain originating in the spine and afflicting the neck and upper extremities may originate from the intervertebral discs, facet joints, spinal cord, nerve roots, vertebrae, ligaments, and muscles. Structures of the cervical spine also have been shown to cause not only pain in the neck and upper extremities but also in the head resulting in cervicogenic headache $(16,17)$.

The earliest relationship of headaches and the cervical spine was made in 1860 by Hilton (18). Cervical discs and facet joints have been shown to be responsible for cervicogenic headache (19-22).

Discography may be used to precisely localize the source of symptoms (17, 23-25). Magnetic resonance imaging (MRI) and computed tomography (CT) scanning can be considered precise when symptoms are radicular, with pain from a compressed nerve root. In the absence of objective neurological deficits or electrodiagnostic findings, the correlation of MRI findings with a patient's symptoms is at best imprecise. The requirement for cervical discography to localize and identify the source of cervicogenic pain was illustrated in the paper by Schellhas et al in 1996 (23). They studied both asymptom- atic and chronic pain sufferers, concluding that significant lesions were missed by MRI and that it could not be relied upon to identify the source of cervicogenic pain.

Once a pain-generating pathological cervical disc has been identified and localized as a pain-producing disc, there have been several different techniques advocated for treatment. A series of patients with cervical disc herniation and radicular pain were treated by low-dose chemonucleolysis combined with automated percutaneous nucleotomy by Hoogland and Scheckenbach (26). Bonaldi et al (27), in 1994 , reported the successful use of nucleotome instrumentation for percutaneous disc decompression in cervical discs. Knight et al (28), in 2001, reported a two year prospective outcome study using percutaneous laser disc decompression in the management of cervical disc prolapse and discographically confirmed discogenic pain in association with radicular pain with $51 \%$ of patients noting significant improvement and $26 \%$ having functional improvement. The sustained nature of the improvement after long-term pre-procedural symptoms in this cohort of $76 \%$ of patients ruled out any placebo effect. Chiu et al (29), in 2000, reported $94.5 \%$ of patients treated with laser thermodiskoplasty (laser energy shrinkage of disc material in cervical discs) had good to excellent results at an average follow-up of 25 months. Only $5.5 \%$ of 200 patients treated remained symptomatic with persistent neck pain. 
Feng and Schofferman (30), in 2003, formulated a detailed algorithm for the evaluation and treatment of patients with cervicogenic headaches.

Extensive literature search has not shown any published reports of randomized trials, prospective trials, retrospective trials, or case reports of treatment of cervical discogenic pain with radiofrequency coblation technology. Hence, we present a case report describing a patient with neck pain, upper extremity pain, and headache following a whiplash injury refractory to drug therapy, physical therapy, and fluoroscopically directed epidural steroid injections.

\section{CAse Report}

A 42-year-old female presented with complaints of neck pain, headache, and upper extremity pain, which started following a motor vehicle injury in which she was rear-ended. The radiologist, comparing the MRI of 2002 with a prior exam done previously in 2000 , described "mild spondylitic changes in the mid and lower cervical spine. Since the prior exam, the left paracentral disc bulge seen at C5/ 6 has become more broad based and central and causes effacement of the anterior subarachnoid space but no deformity of the underlying cervical spinal cord at C5/ C6. There is now minimal right paracentral disc protrusion at $\mathrm{C} 6 / \mathrm{C} 7$ that causes effacement of the anterior subarachnoid space but no deformity of the underlying cervical spinal cord. No change in the narrowing of the left lateral neural foramen at $\mathrm{C} 2 / \mathrm{C} 3$ and $\mathrm{C} 4 / \mathrm{C} 5$. Remainder normal."

The patient exhausted extensive conservative therapy, which she had tried for the past six years. She had been evaluated by a neurosurgeon who did not recommend any surgery. She was referred by her family physician for evaluation and management. During physical examination findings were significant for localized tenderness in the occipital and suboccipital areas on the left side and in the lower posterior cervical region at left paraspinal and midline interspinous area. There were no neurological deficits.

Following the initial evaluation, the patient was treated again with conservative modalities, as well as interventional techniques utilizing diagnostic facet joint nerve blocks and fluoroscopically directed interlaminar epidural steroid injections.

Subsequently, she underwent an- other MRI, which showed no significant changes, along with a second surgical opinion. The second surgical opinion also did not recommend surgical intervention. At this time, discography was contemplated as a further diagnostic procedure.

Although she was symptomatic with some MRI correlations, the MRI findings could not pinpoint the cause of her pain. It was essential to localize the pain-generating site. The structures, which could be a potential source of her pain and required investigation, were the discs stated to be abnormal in the MRI reports.

The patient underwent provocative discography at C4/C5, C5/C6 and C6/ C7. The result of discography identified the $\mathrm{C} 6 / \mathrm{C} 7$ disc as the main pain-generating disc level. The patient did not have any pain at $\mathrm{C} 4 / \mathrm{C} 5$. At $\mathrm{C} 5 / \mathrm{C} 6$ she did have some pain but the intensity was less than at C6/C7. Based on this finding, disc decompression was recommended.

During the discussion of treatment options with her the following points were stressed: (1) Cervicogenic headache is not an uncommon problem in a patient with a whiplash pain syndrome (1622). However, except for the case report of left-sided C6/C7 herniation and ipsilateral cervicogenic headache by Michler et al (31), no other reports during the online literature search implicating $\mathrm{C} 6 / \mathrm{C} 7$ disc herniation as a source of cervicogenic headache were found; (2) Cervical region disc decompression using radiofrequency coblation technology to treat cervicogenic headache has not been previously reported in the literature.

Various methods of percutaneous disc decompression were discussed with her, among them laser and coblation technology. The patient had the choice to undergo this procedure using laser energy or the newly approved radiofrequency coblation technique, also called plasma discectomy or Nucleoplasty ${ }^{\circledR}$. She chose to undergo decompression by radiofrequency coblation.

Percutaneous disc decompression at C6/C7 was performed.

\section{Procedure Detalls}

The patient was taken to the operating room and was placed in the supine position with routine monitoring. The right side of the neck was prepped and draped in a sterile fashion. During the procedure she received monitor anesthesia care (MAC) with mild sedation, re- taining the ability to communicate. Under fluoroscopic guidance, the target site was identified (the area just medial to the uncovertebral junction of $\mathrm{C} 7$ in oblique view). The skin surface was anesthetized with $1 \%$ lidocaine. Skin puncture was made with an 18-gauge needle. A 19-gauge introducer cannula was introduced and carefully advanced toward the target point. By applying digital pressure soft tissues were displaced from the vertebral body and the disc space on the right side. In order to palpate the bony surface of the vertebral body, structures medial to the puncture sites were displaced medially and those lateral to it were pushed laterally. Fluoroscopic guidance was used frequently to localize the cannula entry site. As the cannula contacted the bony surface of the C7 body it was positioned close to the uncovertebral junction. When the tip appeared to be just medial to the uncovertebral junction it was directed to enter the intervertebral disc (Fig.1). Once the cannula entered the disc tissue, it was advanced slowly, carefully checking the position of the tip in the anteroposterior (AP) and lateral projections. The cannula tip was then advanced sufficiently posterior and toward the left side and adjusted such that the lesioning loop would be inside the nucleus (Fig. $2 \& 3$ ).

The ArthroCare Perc-DC ${ }^{\mathrm{TM}}$ Spine Wand was inserted into the introducer cannula. The positioning of the loop was checked in the AP and lateral projections. Lesioning was performed at two sites. The first site was slightly off the midline toward the left side as seen in AP projection (Fig 2) and in the lateral projection it was slightly deeper (more postiterior) than the center portion of the disc (Fig. 3). The second position was closer to the midline in AP projection (Fig.4) and closer to the center of the disc in the lateral projection (Fig. 5). Testing was done by pressing the coagulation peddle for $1 / 2$ to $1 \mathrm{sec}$ ond to ensure the integrity of the circuit and proper positiong of the loop. The patient did not report any kind of unpleasant paresthesia or unpleasant pain symptoms. Lesioning at the two sites was then performed by rotating the loop 180 degrees over the duration of 3 to 5 seconds.

After removal of the needle, pressure was applied to the puncture site. The site was cleansed and dressed in sterile fashion. No complications were noted during recovery or post-discharge.

The procedure was successfully com- 


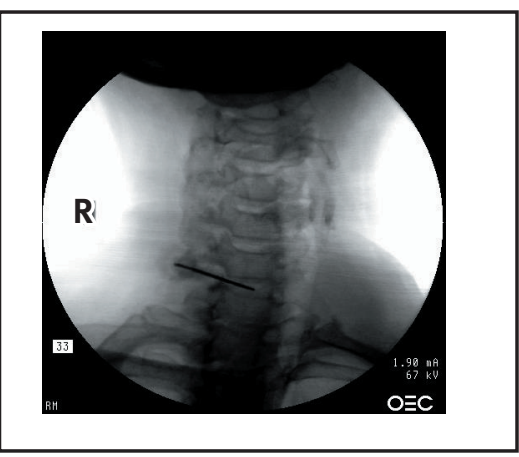

Fig 1. Oblique view of cervical spine and Cannula inside the disc at $\mathrm{C6}$ - C7

pleted and the patient reported $100 \%$ pain relief. Her pain drawings and score show pre-procedural pain as 10/10; post-procedural pain was $0 / 10$.

Six months post-procedure she has reported $100 \%$ relief from the headache and $85 \%$ relief from the neck pain and upper extremity pain. Functional improvement has allowed her to return to work full time.

\section{DISCUSSION}

Percutaneous disc decompression has been performed and extensively reviewed in the lumbar region (32-35). It has been performed using chymopapain and laser energy in the cervical region (35-40). Radiofrequency energy was approved for use in the cervical region recently (ArthroCare Corp., Sunnyvale CA). Common to all methods is an equivalent mode of action - the volumetric reduction of disc material. Radiofrequency cobla-

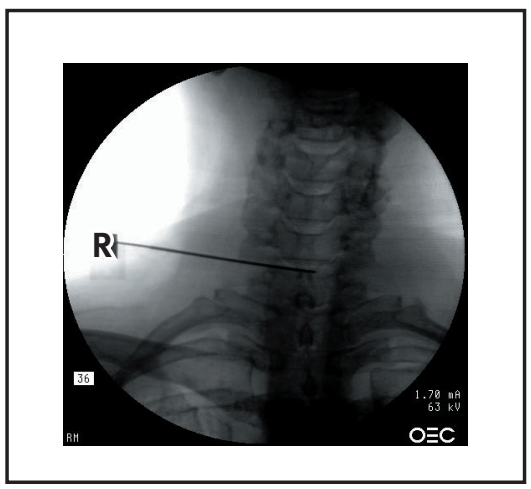

Fig 4. Cannula and PercDC Spine Wand in the left half of the disc at C6-C7 as seen in AP projection closer to center of the disc.

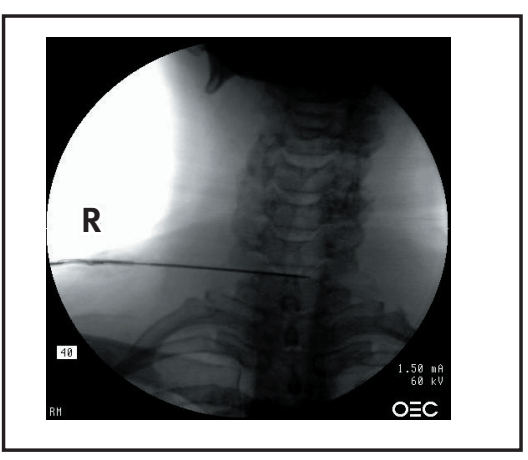

Fig 2. Cannula and PercDC Spine Wand in the left half of the disc at C6-C7 as seen in AP projection.

tion has been shown to achieve the volumetric reduction by dissolution of chemical bonds and conversion of tissue into elemental gases, which are eliminated via the hollow cannula.

In the case of this patient, the exact mechanism of resolution of symptoms cannot be elucidated precisely. It can be hypothesized that dissolution of disc material resulted in the decompression of the disc and hence resulted in relief of pain.

This procedure is easily performed on an out-patient basis under conscious sedation and does not compromise the performance of an open surgical procedure should one become necessary. The successful outcome in this patient should lead to further study of the percutaneous disc decompression technique to alleviate chronic discogenic cervicalgia, brachialgia and cervicogenic headache.

One can argue that the spontaneous resolution of symptoms occurs over a time span of six months to a year. Bush

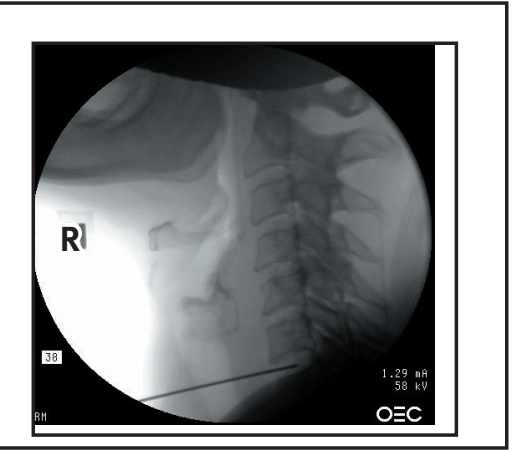

Fig 5. Lateral view of Cannula and PercDC Spine Wand inside the disc at C6-C7, positioned in the posterior half of the disc closer to center of the disc.

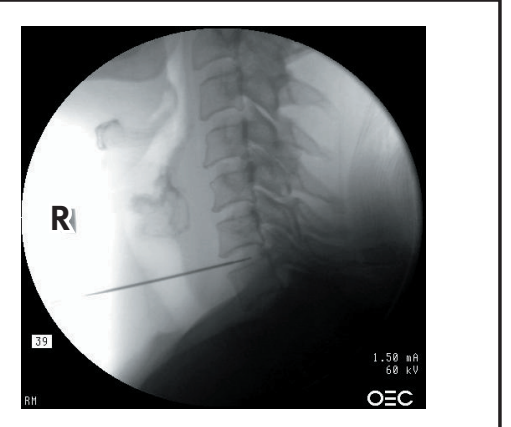

Fig 3. Lateral view of Cannula and PercDC Spine Wand inside the disc at C6-C7, positioned in the posterior half of the disc.

et al (41), showed that most cervical disc herniations regressed over the time of one year. In this patient with symptoms lasting over six years, it is not likely that her symptoms would have resolved without intervention.

The natural course of cervical disc herniation varies widely. Surgery cannot guarantee relief especially when treatment is for neck pain. An extensive review of surgically and conservatively treated patients was done by Heckman et al (42) over an eleven year period ending in 1995. They studied the functional outcomes of patients with cervical herniated intervertebral discs with radiculopathy. Signs and symptoms of brachialgia, sensory disorders, reflex abnormalities, motor weakness and cervicalgia were prospectively assessed. MRI was utilized to characterize cervical disc pathology. During an average follow-up time of 5.5 years 39 patients were treated using only conservative methods, and 21 had surgical discectomy. Symptomatology was assessed and reported in each of these two groups. In each category, brachialgia, sensory disorder, reflex abnormality and motor weakness either normalized or improved equivalently while cervicalgia was found to be the most difficult to treat. Two thirds of the conservatively treated patients did not improve and $80 \%$ of the surgically treated patients similarly showed no improvement in cervicalgia symptoms. The authors concluded that conservative treatments were successful though persistent cervicalgia was common. This finding was illustrated by our patient, who had chronic symptoms while being treated conservatively for a similar period of time. 


\section{ConCLUSION}

The patient described here had chronic cervical discogenic pain, refractory to conservative and interventional management. She was successfully treated with percutaneous disc decompression. She was one of the patients for whom minimally invasive therapy was the only remaining option. She found relief after undergoing percutaneous disc decompression using the radiofrequency coblation technique.

\section{Author Affiliation:}

\section{Vijay Singh, MD}

Medical Director

Pain Diagnostics Associates

1601 Roosevelt Rd.

Niagara, Wisconsin 54151

E-mail: vsingh@netnet.net

\section{REFERENCES}

1. Manchikanti L, Staats P, Singh V et al. Evidence-based practice guidelines for interventional techniques in the management of chronic spinal pain. Pain Physician 2003; 6:3-80.

2. Côté DC, Cassidy JD, Carroll L. The Saskatchewan Health and Back Pain Survey. The prevalence of neck pain and related disability in Saskatchewan adults. Spine 1998; 23:1689-1698.

3. Côté DC, Cassidy JD, Carroll L. The factors associated with neck pain and its related disability in the Saskatchewan population. Spine 2000; 25:1109-1117.

4. Bovim G, Schrader H, Sand T. Neck pain in the general population. Spine 1994; 19: 1307-1309.

5. Lau EMC, Sham A, Wong KC. The prevalence of and risk factors for neck pain in Hong Kong Chinese. J Public Health Med 1996; 18:396-399.

6. Ariens GA, Borghouts JA, Koes BW. Neck pain. In Crombie IK, Croft PR, Linton SJ, Le Resche L, von Korff M (eds). Epidemiology of Pain. IASP Press, Seattle, 1999.

7. Frederiksson K, Alfredsson L, Koster M et al. Risk factors for neck and upper limb disorders: Results from 24 years of follow up. Occup Environ Med 1999; 56:59-66.

8. Linton SJ, Hellsing AL, Hallden K. A population based study of spinal pain among 35-45-year old individuals. Spine 1998; 23:1457-1463

9. Ylinen J, Ruuska J. Clinical use of neck isometric strength measurement in rehabilitation. Arch Phys Med Rehabil 1994; 75: 465-469.

10. Hellsing A, Bryngelsson I. Predictors of musculoskeletal pain in men. A twenty- year follow-up from examination at enlistment. Spine 2000; 25:3080-3086.

11. Miles K, Maimaris C, Finlay D et al. The incidence and prognostic significance of radiological abnormalities in soft tissue injuries to the cervical spine. Skeletal Radiol 1988; 17:493-496.

12. Norris S, Watt I. The prognosis of neck injuries resulting from rear-end vehicle collisions. J Bone Joint Surg Br 1983; 65:608611.

13. Hildingsson C, Toolanen G. Outcome after soft-tissue injury of the cervical spine: A prospective study of 93 car accident victims. Acta Orthop Scand 1990; 61:357359.

14. Hodgson S, Grundy M. Whiplash injuries: Their long-term prognosis and its relationship to compensation. Neuro Orthopedics 1989; 7:88-91.

15. Kuslich SD, Ulstrom CL, Michael CJ. The tissue origin of low back pain and sciatica: A report of pain response to tissue stimulation during operation on the lumbar spine using local anesthesia. Orthop Clin North Am 1991; 22:181-187.

16. Biondi DM. Cervicogenic headache: Mechanisms, evaluation and treatment strategies. J Amer Osteopath Assoc 2000; 100: S7-S14.

17. Bogduk N, Aprill C. On the nature of neck pain, discography, and cervical zygapophysial joint blocks. Pain 1993; 54:213-217.

18. Haldeman S, Dagenais S. Cervicogenic headaches: a critical review. Spine / 2001; 1:31-46.

19. Peterson DI, Austin GM, Dayes LA. Headache associated with discogenic disease of the cervical spine. Bull Los Angeles Neurol Soc 1975; 40:96-100.

20. Barnsley L, Lord SM, Wallis BJ et al. The prevalence of chronic cervical zygapophyseal joint pain after whiplash. Spine 1995; 20:20-26.

22. Lord SM, Barnsley L, Wallis BJ et al. Chronic cervical zygapophysial joint pain with whiplash: A placebo-controlled prevalence study. Spine 1996; 21:1737-1745.

22. Manchikanti L, Singh V, Rivera J et al. Prevalence of cervical facet joint pain in chronic neck pain. Pain Physician 2002; 5:243-249.

23. Schellhas KP, Smith MD, Gundry CR et al. Cervical discogenic pain. Prospective correlation of magnetic resonance imaging and discography in asymptomatic subjects and pain sufferers. Spine 1996; 21:300-312.

24. Bogduk N. Diskography. APS / 1994; 3: 149-154.

25. Fortin JD. Precision diagnostic disc injections. Pain Physician 2000; 3:271-288.

26. Hoogland T, Scheckenbach C. Low-dose chemonucleolysis combined with percutaneous nucleotomy in herniated cervical discs. J Spinal Disord 1995; 8:228-232.

27. Bonaldi G, Minonzio G, Belloni $G$ et al. Per- cutaneous cervical discectomy: preliminary experience. Neuroradiology 1994; 36:483-486.

28. Knight MT, Goswami A, Patko JT. Cervical percutaneous laser disc decompression: preliminary results of an ongoing prospective outcome study. I Clin Laser Med Surg 2001; 19:1-2.

29. Chiu JC, Clifford TJ, Greenspan M et al. Percutaneous microdecompressive endoscopic cervical discectomy with laser thermodiskoplasty. Mt Sinai J Med 2000; 67: 278-282.

30. Feng FL, Schofferman J. Chronic neck pain and cervicogenic headaches. Curr Treat Options Neurol 2003:5:493-498.

31. Michler RP, Bovim G, Sjaastad O. Disorders in the lower cervical spine. A cause of unilateral headache? A case report. Headache 1991; 31:550-551.

32. Sharps LS, Issac Z. Percutaneous disc decompression using Nucleoplasty. Pain Physician 2002; 5:121-126.

33. Singh V, Piryani C, Liao K et al. Percutaneous disc decompression using coblation (Nucleoplasty) in the treatment of chronic discogenic pain. Pain Physician 2002; 5:250-259.

34. Singh V, Piryani C, Liao K. Evaluation of percutaneous disc decompression using coblation in chronic back pain with or without leg pain. Pain Physician 2003; 6: 273-280.

35. Choy DS. Percutaneous laser disc decompression (PLDD): A first line treatment for herniated discs. I Clin Laser Med Surg 2001; 19:1-2.

36. Siebert W. Percutaneous laser discectomy of cervical discs: preliminary clinical results. I Clin Laser Med Surg 1995; 13:205-207.

37. Schofferman J, Garges K, Goldwaithe N et al. Upper cervical anterior discectomy and fusion improves discogenic cervical headaches. Spine 2002; 27:2240-2244.

38. Li J, Cheng L, Hu H et al. Percutaneous cervical discectomy: A report of 25 cases. Zhongguo Yi Xue Ke Xue Yuan Xue Bao 1996; 18:199-204.

39. Kotilainen E. Percutaneous nucleotomy in the treatment of cervical disc herniation: report of three cases and review. Minim Invasive Neurosurg 1999; 42:152-155.

40. Harada J, Dohi M, Fukada K et al. CT-guided percutaneous disc decompression (PLDD) for cervical disc hernia. Radiat Med 2001; 19:263-266.

41. Bush K Chaudhuri R, Hillier $S$ et al. The pathomorphologic changes that accompany the resolution of cervical radiculopathy. A prospective study with repeat magnetic resonance imaging. Spine 1997; 22:183-186.

42. Heckman JG, Lang CJ, Zobelein I et al. Herniated cervical discs with radiculopathy: an outcome study of conservatively or surgically treated patients. I Spinal Disord 1999; 12:396-401. 